\title{
Seismic interpretation of unconventional hydrocarbon reservoirs in the central portion of the Recôncavo Basin (NE of Brazil)
}

Daniel Bono R. Vilas Boas*, INCT-GP/IGEO/UFBA, Paulo Augusto V. D. Souza, INCT-GP/IGEO/UFBA.

Copyright 2019, SBGf - Sociedade Brasileira de Geofísica

This paper was prepared for presentation during the $16^{\text {th }}$ International Congress of the Brazilian Geophysical Society held in Rio de Janeiro, Brazil, 19-22 August 2019.

Contents of this paper were reviewed by the Technical Committee of the $16^{\text {th }}$ International Congress of the Brazilian Geophysical Society and do not necessarily represent any position of the SBGf, its officers or members. Electronic reproduction or storage of any part of this paper for commercial purposes without the written consent of the Brazilian Geophysical Society is prohibited.

\section{Abstract}

The work is based on a seismostratigraphic interpretation of $3 \mathrm{D}$ and well log data, aiming the identification of regions with greater potential of non-conventional reservoirs, especially shale gas, in the central portion of the Recôncavo Basin (between the Quiricó Platform and Miranga Low). The interpretation used a sequence stratigraphy model applied to rift basins, in order to identify moments of greater expansion of the lacustrine systems, and thus to be considered as regions of higher hydrocarbon generation. Seismic attributes, such as amplitude and instantaneous frequency, besides others based on coherence, were used to identify anomalies that suggest the presence of gas.

\section{Introduction}

The hydrocarbons production through the hydraulic fracking directly in the source rock constitutes a process with great development during the XXI century. Source rock therefore assumes the character of non-conventional reservoirs, especially when there is high organic content and a high susceptibility to fracturing (especially in the presence of faults, fractures and cracks).

The Recôncavo Basin is considered a mature basin, with extensive exploratory history. However, there are few studies on the potential of non-conventional reservoirs present in the basin, and this type of production has not yet been used in any of the Brazilian sedimentary basins, and is therefore an exploratory barrier still to be broken.

In terms of viability, the Recôncavo Basin was chosen for the study, because it is a basin with proven oil potential, high proximity to large centers, facilitating distribution, relatively less environmental embargoes compared to other regions (such as the Amazon region, or southeastern region above the Guarani aquifer), and presents intervals which the source rock is at low depths.

The present work has as main objective the seismic interpretation of the central region of the Recôncavo Basin. For this, the principles of sequence stratigraphy applied to rifte basins, initially recommended by Prosser (1993), and adapted with the tectonic concepts of
Gawthorpe \& Leeder (2000) developed in the model of Holz et al. (2017).

The present study is part of the development of the research project GASBRAS - Support to the NonConventional Gas Network in Brazil (USP Agreement, UFBA, UFMG, UFRGS, UERJ, UENF); developed with the INCT-GP / IGEO / UFBA.

\section{Study area / Data base}

The study area is comprised in the central portion of the Recôncavo Basin (BA, Brazil), between the transcurrent lines of Mata-Catu and Itanagra-Araçás, in a region between the Quiricó Platform and the Miranga Low. The data available to the study consists of a post-stacked seismic polygon of approximately $150 \mathrm{~km}^{2}$ and data from 7 wells (see Figure 1), all of them publicly provided by the ANP.

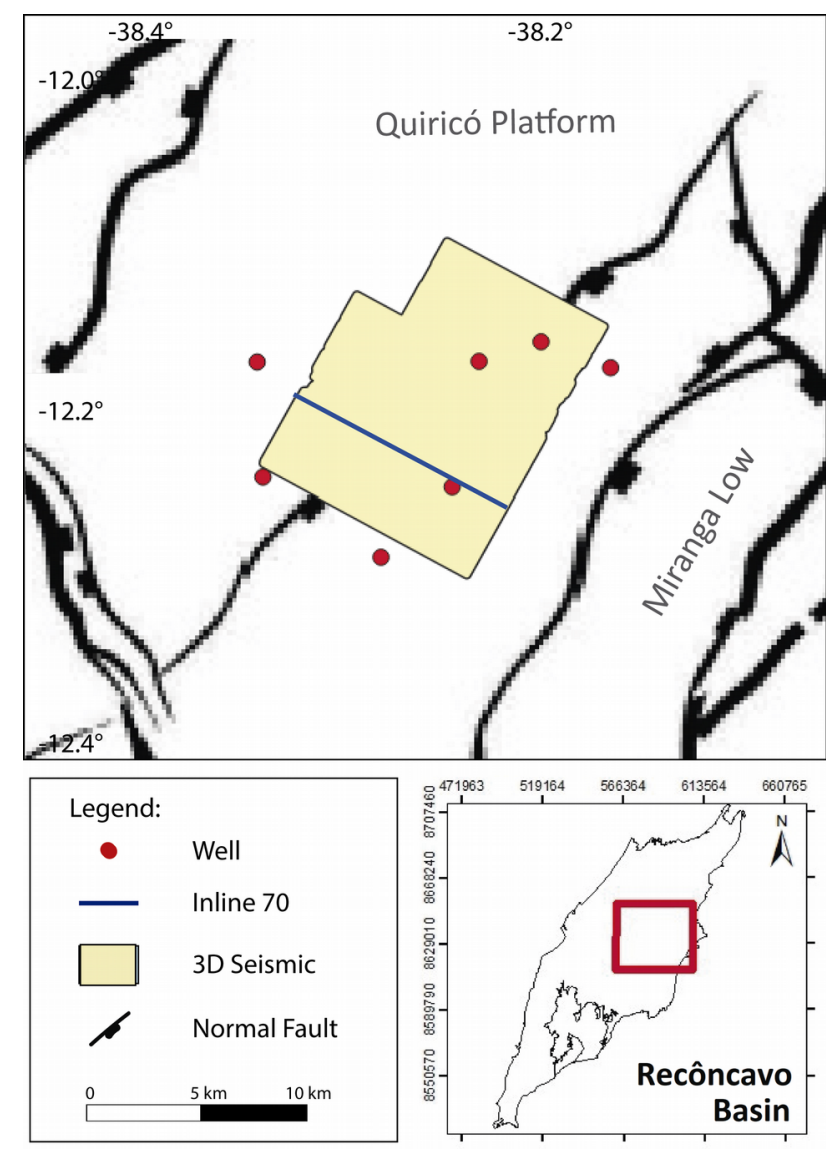

Figure 1 - Data base in the Quiricó Platform and Miranga Low, central portion of Recôncavo Basin (BA, Brazil). 


\section{Methods}

The seismic and well data were all analyzed using the OpendTect seismic interpretation software, where the wells were tied to the seismic sections through the making of synthetic seismograms. The original post-stack data pass through a localized velocity fan filter, which allowed a considerable increase of continuity, and gain in reflections of high depths, as can be seen in comparison with figures $4 A$ and $4 B$. Several seismic attributes of the complex trace were also calculated, among them: instantaneous amplitude (envelope), phase and frequency, TecVA, similarity, energy, sweetness, among others, which were used both in the seismostratigraphic analysis and in the subsequent evaluation of anomalies indicating potential of unconventional reservoirs.

Throughout the seismic interpretation the sequence stratigraphy model for rifte-type basins of $\mathrm{Holz}$ et al. (2017), where tectonics assumes the main role of creating agent of accommodation space. This aspect characterizes the so-called tectonic systems tracts, where the rift development (RDST) and rift termination systems tract (RTST) were evaluated within the third-order depositional sequences of the syn-rift phase. The first one is characterized by expansion of the lacustrine system and general characteristic retrogradation to pleasant, while the second presents a progradational aspect, with an increase of the fluvio-deltaic systems in front of the lacustrine. These tracts have as limit between them the maximum rifting surface (MRS), which represents the moment of greatest expansion of the lacustrine environment, and thus, greater argilosity (interpreted as higher values of gamma ray logs) and presents as a downlaps surface along the seismic sections.

\section{Seismic interpretation}

Stratigraphic analysis began with the construction of well correlation sections, followed by the interpretation of the 3D seismic data. In structural terms, the interpreted seismic cube is crossed by two normal faults that cut through the entire rift section, with displacements less than $300 \mathrm{~ms}$.

Basically, three third-order depositional sequences were identified along the rift phase, called the Rift 1, Rift 2 and Rift 3 sequences, bounded lower by the RU1, RU2 and RU3 unconformities, respectively. Within the first two sequences were identified in the well analysis by the change of the retrogradational to progradational pattern (as can be seen in the gamma ray well profile in Figure 3), marked respectively by the MRS1 and MRS2 maximum rifling surfaces. These were also identified as downlap surfaces in the sections of the seismic polygon. The summary of the seismostratigraphic interpretation is presented in comparison with the chronostratigraphic chart of the Recôncavo Basin of Silva et al. (2007), shown in Figure 2.

Therefore, the intervals of greater hydrocarbon generation potential were associated to the moments of greater expansion of the lacustrine system, intervals of rift development: RDST1 and RDST2, due to presenting possibly reducing environment, and thus greater preservation of organic matter, as well as greater sedimentary thickness in order to facilitate the maturation conditions of the organic matter, and thus greater generation of hydrocarbons. The ranges described are highlighted in Figure 3.

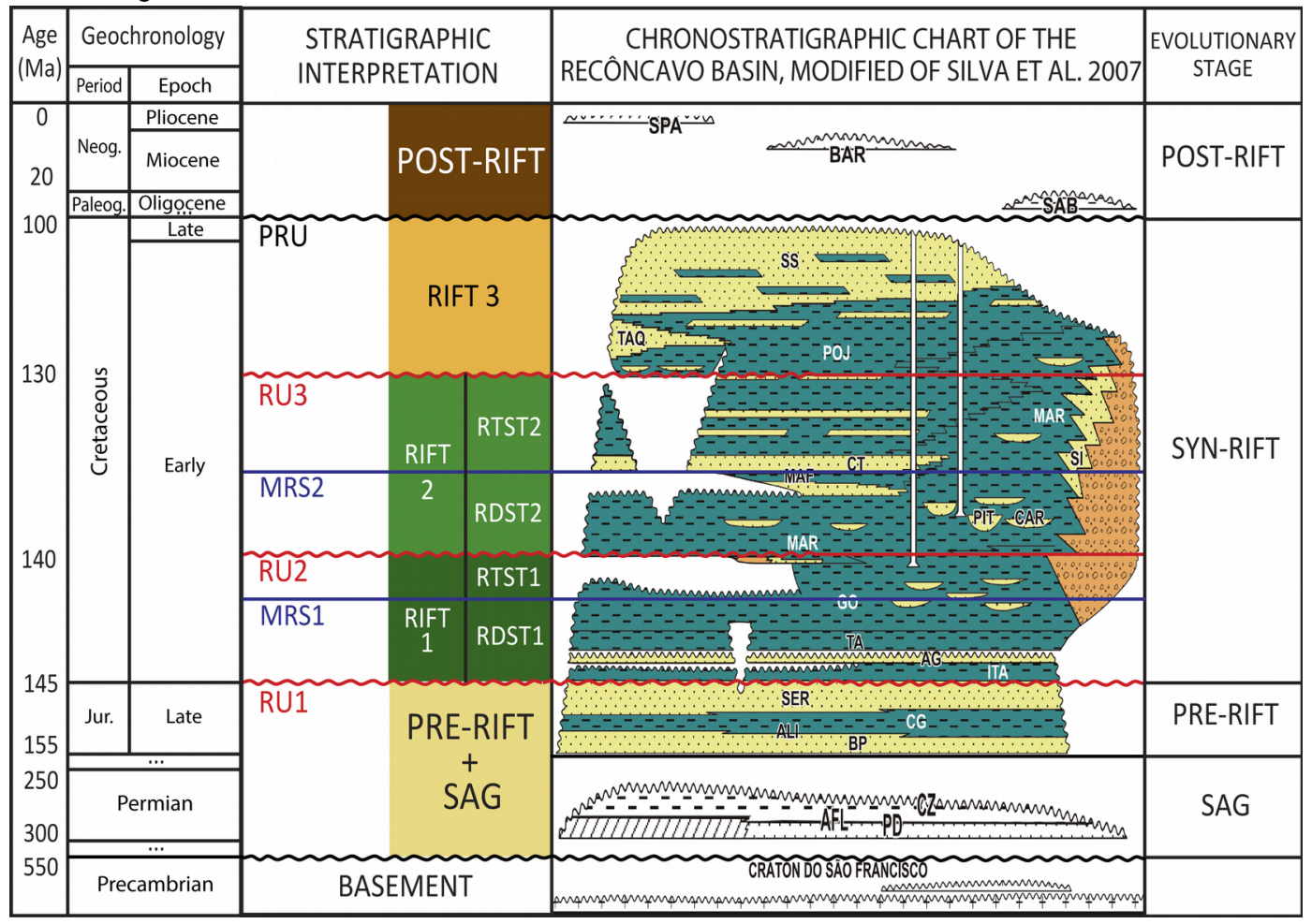

Figure 2 - Chronostratigraphic model of the Recôncavo Basin, modified from Silva et al. (2007). 


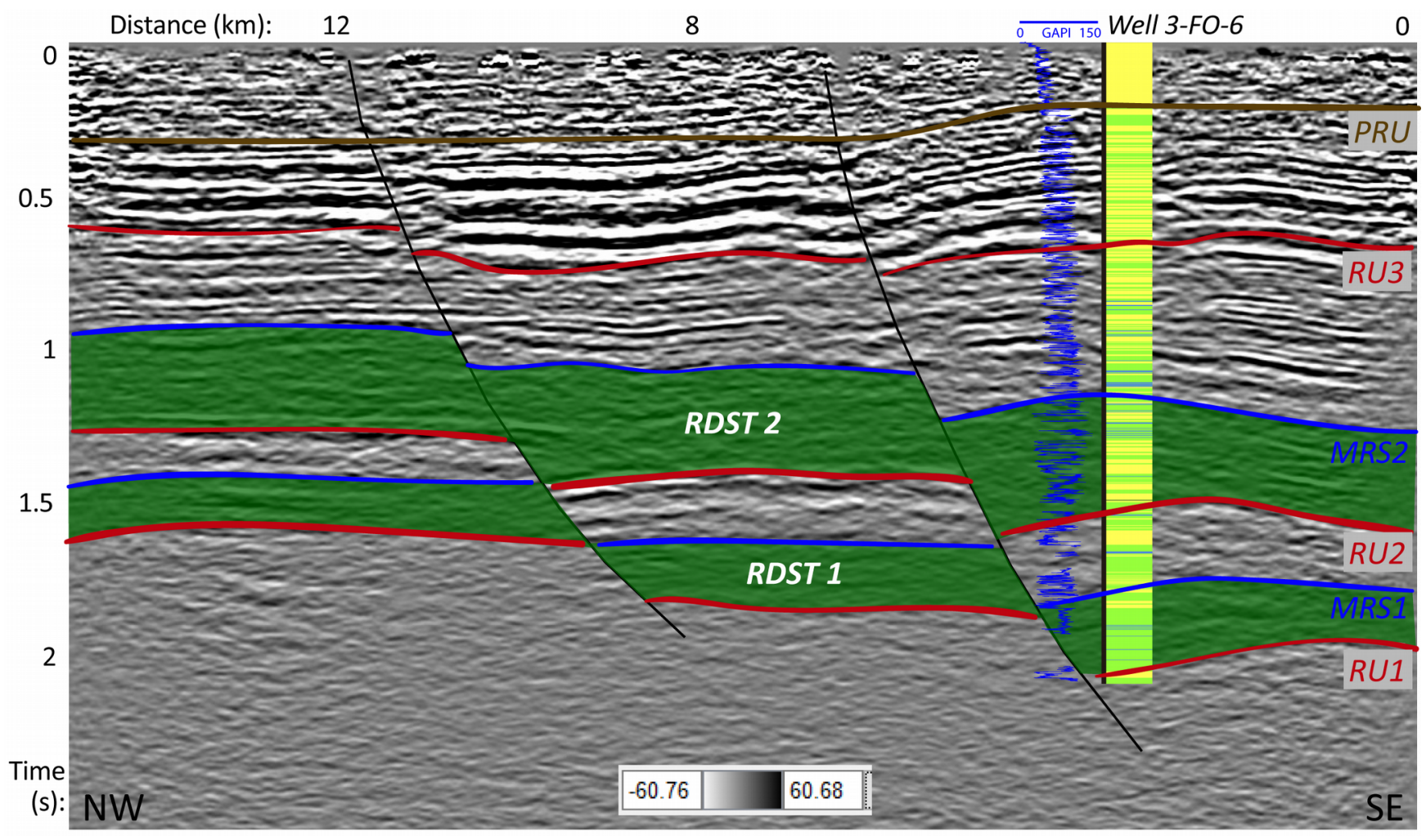

Figure 3 - Seismic interpretation of Inline 70, with the Well 3-FO-6 tied. The rift development systems tracts (RDST1 and RDST2) are highlighted in green, indicating the regions with the highest source potential.

\section{Seismic attributes analysis}

After the stratigraphic analysis, and thus defined the intervals of greater hydrocarbon generation potential (RDST1 and RDST2), the interpretation followed for the analysis of seismic attributes of the complex trace, especially within the interval of these regions.

Several seismic attributes such as instantaneous amplitude (envelope), phase and instantaneous average frequency, TecVA (Amplitudes Volume Technique, or pseudo relief), similarity (measure of coherence) and the attribute called sweetness (Hart, 2008) were used. This can be calculated as:

$$
S=E / \sqrt{f}
$$

$E$ is the envelope (instantaneous amplitude) and $f$ is the instantaneous average frequency.

By comparing the envelope attributes, mean instantaneous frequency and sweetness with the range of greatest generation potential interpreted in inline 70 (figures 4C, 4D e 4E), it is possible to identify positive sweetness anomalies within the range of $1 \mathrm{~s}$ and $2 \mathrm{~s}$ (Figure 4E), confined within the developmental range of Rift 2 (RDST2). This anomaly suggests a high gas presence and, compared to the gamma ray and trough samples in the well profiles, it is possible to identify which part of these anomalies are associated with rocks such as shallow lake shales.

Anomalies of low similarity, especially near faults, can also indicate regions of shales more susceptible to fracturing, which can be seen within the range of $1 \mathrm{~s}$ to $2 \mathrm{~s}$, in figure $4 \mathrm{~F}$.

\section{Conclusions}

The seismostratigraphic interpretation identified three third-order depositional sequences within the rift phase, and internal to the first two sequences, two lacustrine system development intervals, the rift development systems tract of rift 1 (RDST1) and rift 2 (RDST2). These were then considered the portions most prone to hydrocarbon generation, using the best conditions of sediment accommodation space and reducing environment, thus allowing greater preservation of organic matter, as well as a sedimentary package above to favor the entrance of deposits in the gas and oil windows.

Then, the sweetness anomalies identified along the RDST2 range, suggest the possibility of shales with good generation potential that may present higher gas content, which results in both high impedance contrast acoustics with neighboring deposits (high instantaneous amplitude) and commonly lower frequencies. The region of the anomalies therefore suggests the main targets for the presence of unconventional reservoirs in the region, especially related to shale gas. 


\section{Acknowledgements}

The authors thank INCT-GP/IGEO/UFBA for all material and scientifically resources provided for the study, to FINEP for founding the GASBRAS Project, to which the present work belongs, to CNPq for the researcher scholarship.

\section{References}

Gawthorpe, R. L., \& Leeder, M. R. (2000). Tectonosedimentary evolution of active extensional basins. Basin Research, 12(3-4), 195-218.
Hart, B. S. (2008). Channel detection in 3-D seismic data using sweetness. AAPG bulletin, 92(6), 733-742.

Holz, M., Vilas-Boas, D. B., Troccoli, E. B., Santana, V. C., \& Vidigal-Souza, P. A. (2017). Conceptual Models for Sequence Stratigraphy of Continental Rift Successions. In Stratigraphy \& Timescales, Vol. 2, pp. 119-186.

Prosser, S. (1993). Rift-related linked depositional systems and their seismic expression. Geological Society, London, Special Publications, 71(1), 35-66.

Silva, O. D., Caixeta, J. M., Milhomem, P. D. S., \& Kosin, M. D. (2007). Bacia do Recôncavo. Boletim de Geociências da PETROBRAS, 15(2), 423-431.
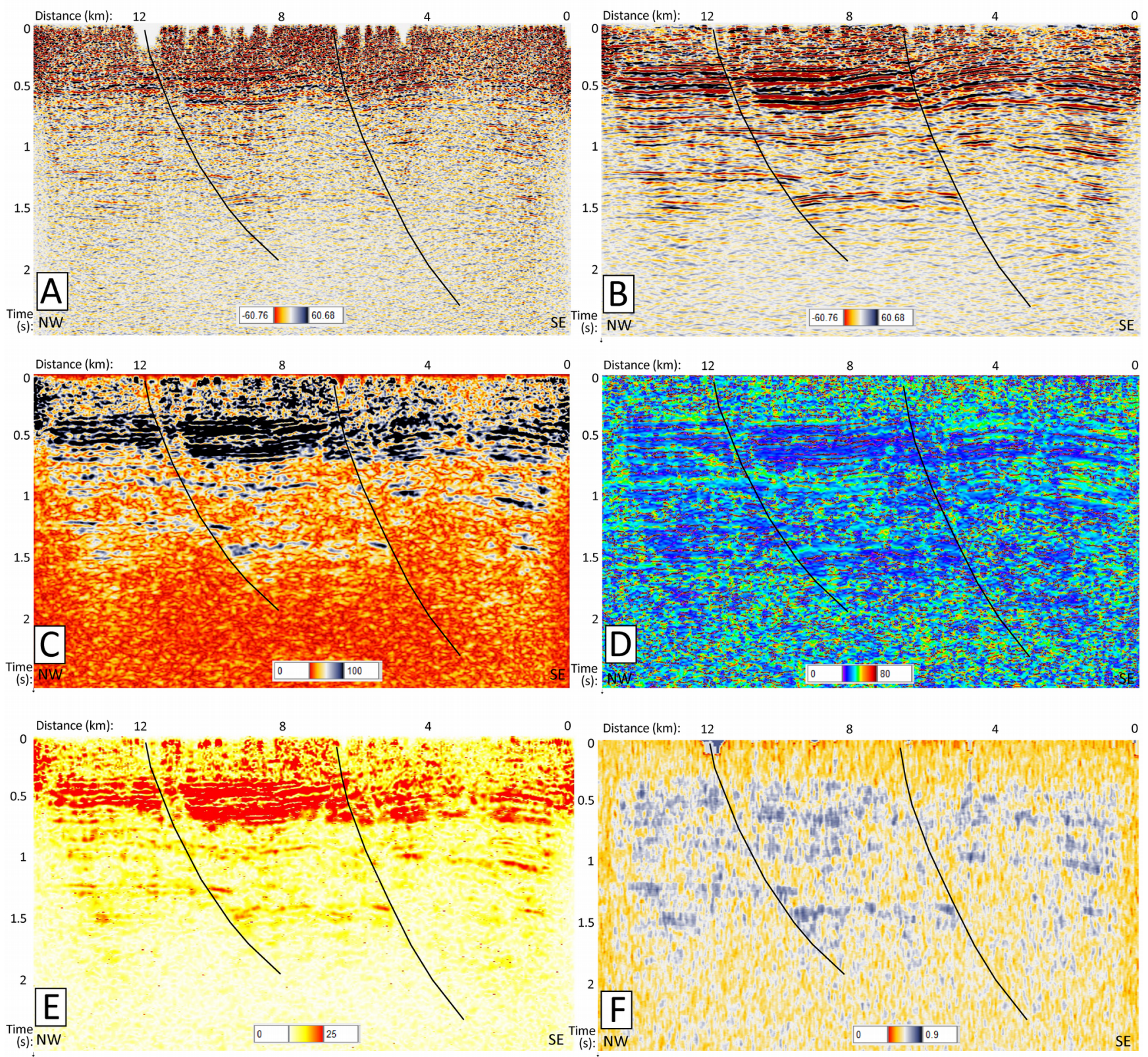

Figure 4 - Inline 70, with the following attributes: (A) original amplitude; (B) filtered amplitude; (C) envelope; (D) instantaneous average frequency; $(E)$ sweetness; $(F)$ similarity. 